\title{
Intervening Anatomic Structure
}

National Cancer Institute

\section{Source}

National Cancer Institute. Intervening Anatomic Structure. NCI Thesaurus. Code C87032.

An artifact resulting from the presence of another body structure between the target and the receiver. 